\title{
SOBRE LAS PRIMERAS APARICIONES DE CONSTRUCCIONES PREPOSICIONALES ANTE $Q U E$ COMPLETIVO EN ESPAÑOL MEDIEVAL. FACTORES DETERMINANTES ${ }^{1}$
}

ana SerRadilla Castaño

0. La aparición de preposición ante QUE completivo con verbos que presentan el esquema preposicional con complementos nominales y de infinitivo se ha venido situando tradicionalmente en el siglo XVII; así, autores como S. Bogard y C. Company (1989) aseveran:

«Nos parece especialmente interesante la estructura sin preposición porque es la única que admite el español desde sus orígenes hasta el siglo XVII» (p. 259).

y en nota señalan:

«Del total del material analizado, sólo dos ejemplos en el español medieval y uno en el siglo XVI escapan a esta generalización» (p. 259, nota 1).

Esta es la misma postura adoptada por M. Ramos Méndez (1989) y Serafina García (1990) y la que anteriores estudiosos como Cano Aguilar (1985) o,

1 Agradecemos a la Fundación Caja de Madrid su colaboración económica, pues ha facilitado, en gran medida, nuestra investigación. 
incluso, Menéndez Pidal exponen en sus trabajos. Para estos autores, la utilización de preposición ante QUE completivo es un fenómeno de incorporación tardía en nuestra lengua. En este artículo queremos destacar la presencia, aunque sea esporádica, de construcciones preposicionales ante QUE completivo ya en el español medieval y demostrar, por lo tanto, que estamos ante un fenómeno más temprano de lo que hasta ahora se había afirmado.

1. Hemos acotado nuestro campo de estudio y trabajamos, básicamente, con los llamados «verbos de entendimiento y lengua»; dentro de este grupo hemos documentado ejemplos de esta construcción cuando el elemento regente es un verbo, un nombre o, incluso, un adjetivo. Estas primeras apariciones suponen ya el comienzo de una construcción que va a ser la habitual en siglos posteriores con determinadas expresiones de régimen preposicional y cuyos orígenes habrá que buscar en la lengua medieval ya que, como hemos señalado, tenemos documentos que apuntan en esta dirección.

- En el español actual, a diferencia de otras lenguas romances, verbos que precisan de una preposición para unirse a su complemento - hablar de, confiar en, creer en, referirse a, maravillarse de, arrepentirse de... - utilizan ésta independientemente de que el complemento sea un nombre, un infinitivo o una oración introducida por QUE. En español medieval, sin embargo, esta tendencia uniformadora del español aún no ha triunfado $y$, mientras complementos nominales o de infinitivo reciben este régimen preposicional, cuando el complemento es una oración completiva, ésta, por regla general, se une directamente al verbo sin utilizar la preposición:

no me maravillo que seas mudable, (Celes. $V$ )

Cata no confies que tu amigo te à de tener secreto. (Celes. XVII)

El so amigo es el que cree en ella e cree que es uerdat (Libr. Compl.

p. 167,140 a)

cuedos que lo podrie//derrocar Jines falla (Alex. 545c)

Triftobolus que dubdas que Rafes fo de guarir (Alex. P. 2234c)

non se podría escusar que non fuese traidor por ello, (Lib. Est. I, p. 178) la ley fabla quel tal ofiçio pueda ser rrenunçiado (Doc. Villa II, 1435, p. 135)

...nin fió que non llegase... (C. Luc. p. 238)

e que agora eran ynformados que no guardauan nin querían guardar la dicha tasa, (Acuerd. Concejo, 1484, p. 353)

Quexáseme que aun verle no quieres (Celes. VII)

que se reçelaba que el toro andara catando... (C. Luc. p. 137)

- Este uso no preposicional de las oraciones complementarias en español medieval es claramente predominante y es el que ha llevado a diversos 
estudiosos a hacer afirmaciones tan tajantes como las que apuntábamos arriba. Por otra parte, esta ausencia de preposición obedece, en gran medida, a la herencia latina. En latín no se asignaba caso a la oración y, por tanto, nunca recibía preposición. Tampoco las demás lenguas romances admitían (ni admiten $)^{2}$ el uso preposicional ante oración. La herencia latina y la similitud con otras lenguas romances, así como la existencia de construcciones como antes que o después que, siempre sin preposición, o la consideración de QUE como nexo suficiente para expresar la relación de subordinación son factores que potencian el mantenimiento de la construcción directa; en español medieval existía una tendencia muy fuerte a considerar el QUE como un subordinante universal, y a ver la preposición como un nexo superfluo. Se tiende a evitar la acumulación de nexos para marcar la relación de subordinación y, en el caso en que el complemento es una oración, QUE cumple por sí solo esta función, por lo cual la preposición sería innecesaria. Esta tendencia a evitar la acumulación de nexos llevaba en ocasiones a omitir incluso la conjunción ya que el subjuntivo puede marcar por sí mismo la subordinación:

quiero e mando non sola mente se entienda en lo que atanne... (Doc. Villa II, 1435, p. 194)

vos lo entiendo rremunerar en merçedes, e mucho vos rruego lo continueys (Doc. Villa III, 1465, p. 173)

nos lleve, le ruego, con los que creyeron. (Celes. p. 8) suplicando a su Alteza mande rreuocar la merçed... (Acuerd. Concejo, 1481, p. 73)

Dada la importancia de la herencia latina y de los otros factores mencionados, la construcción directa va a ser la predominante en el español medieval, pero ésta, que se ha considerado la única posibilidad, convive ya en esta época con los primeros asomos de construcciones preposicionales.

En los textos de los siglos XIII-XV existen, como señalábamos al principio, datos que nos permiten afirmar que el uso de preposición no comienza, como algunos han dicho, en el siglo XVII sino que sus orígenes están en la época medieval.

2. A continuación presentamos los ejemplos que hemos documentado.

- Sustantivo + prep + QUE

2 El portugués sí presenta en algunas ocasiones el régimen preposicional ante QUE, aunque su uso no está tan generalizado como en español actual. 
llegaron (...) los emperadores a Roma con muy grand alegría de que auien conquistas todas las tierras del mundo (P.C.G. I, p. 178, 303) ${ }^{3}$

... que auie muchos en aquella tierra, por razón de que se fazien alli muchas serpientes de departidas naturas et malas (P.C.G. I, p. 102, 135)

Et porque los frutos de la tierra non vienen en cada logar a una sazon por razón de que algunas tierras hi ha que son frias et otras calientes de natura, (Siet. Part. III-2-XXXVII, apud Bartol p. 377)

empero por resçelo de que algunos de su Regno se alzasen contra el... (Crón. Pedro I, 349. 18-25, apud Bogard p. 262) ${ }^{4}$

- Adjetivo + prep + QUE

fuesse pora Roma muy loçano de que uenciera, (P.C.G. I, p. 130, 181 $)^{5}$

\section{- Forma analítica + prep + QUE}

- Forma analítica compuesta por Verbo + Nombre

con la grand sanna e el pesar que ouo de que lo derribara (H." Troyana 75. 22-24, apud Bogard p. 262)

E no suffriera Vespasiano del fazer estas crueldades si non por el grand pesar que auie de quel matara ell hermano (P.C.G. I, p. 132, 181)

et desi sopo en como aquel so uassallo en cuya figura aquel pareciera, que estaua encerrado en la eglesia con uerguenna que auie de que se non acertara en aquella fazienda (P.C.G. II, p. 426, 729)

é porque le semejó que había vergüenza de que no traia manto, (Conq. p. 40)

et iuan antel grandes compannas de joglares cantando las cantigas et diziendo las fablas de que los el uenciera, et contando los logares en que contesciera cada una cosa; (P.C.G. I, p. 122, 172)

3 DE QUE no es temporal en este caso sino que introduce un complemento con un valor cercano a la «causa». En algunos verbos de *entendimiento y lengua» de y por están muy próximas ya que pueden crearse confusiones porque el complemento indica, a la vez, el objeto y el motivo de la acción: arrepentirse, agradecer, alegrarse...

4 Obsérvese que en todos estos casos la preposición utilizada es DE, ya que ésta es la que, habitualmente, utiliza el nombre para unirse a su complemento.

5 Vid. la explicación que se da en la nota 3. 
Sepades que a nos es fecha rrelacion en que vosotros andays de lugar en lugar muchos tiempos e annos (Doc. Villa III, 1499) ${ }^{6}$

$¡ \mathrm{O}$, cuan dichosa me hallaría en que tú y Sempronio... (Celes. VII ${ }^{7}$

e dizien le por esto sus priuados que fazie su plazer en que prometie mucho mas de lo que podie dar, (P.C.G. I, p. 138, 186)

Fijo, assi es que bien deuemos creer que fue juizio de Dios en que tu meresciste dexar la locura de los ydolos; mas tenemos que fue yerro de omne en que quesiste creer que Ihesu Nazareno es Dios, (P.C.G. I, p. 188,318$)^{8}$

Pues ¡qué gozo auria agora él en que le pusiesse yo en algo por mi seruicio... (Celes. XV) ${ }^{9}$

... que darás causa a que seas sentido. (Celes. XII)

diome lugar a que entrase; (Cárcel, p. 165)

no consyntades nin dedes lugar a que los dichos abades... (Acuerd. Concejo 1484$)^{10}$

todas concedieran y vinieran conformes en que las llevara Melibea; assí que se llamara mançana de concordia. (Celes. VI)

6 En este caso, aunque pudiera parecer dudoso, no estamos ante un QUE relativo sino ante una oración completiva. Por regla general, esta construcción aparece sin preposición con idéntica función y significado y en estos casos no se puede dudar de su carácter completivo: y me hizo rrelaçion que vos suçedistes en el ofiçio... (Acuerd. Concejo. 1517!, p. 431); me fizo rrelacion quel Rey don enrrique mi hermano... (Doc. Villa III, 1476, p. 233); Sepades que a nos es fecha rrelacion que a cabsa que el... (id. 1488, p. 315); nos fue fecha relaçion por su peticion, (...) diziendo que... (Contrib. 1495, p. 86); y agora nos es fecha relaçcion que las justiçias... (id. 1537!, p. 177). Es la presencia de la preposición EN, en lugar de DE, más esperable, la que provoca la confusión.

7 Este ejemplo y los dos siguientes también plantean ciertos problemas de interpretación pero, según nuestra opinión, estamos ante una función completiva. TARR (1922, p. 164) propone este ejemplo como un caso de complemento extrínseco (según su denominación, estaría hablando de un complemento regido pero muy cercano al C.C. porque la preposición aporta algún valor) que expresa una relación con cierto grado de valor causal.

8 TARR (1922, p. 168-69) cita este ejemplo. Para él la forma en que es igual a que y su presencia estaría justificada por una analogia: «It seems probable that the use of the en que clause as equivalent to the que clause is an analogical extension of the use of the prepositional infinitive with EN as equivalent to the simple infinitive».

9 Es posible percibir aquí cierto valor condicional; este valor, no obstante, está muy difuminado y podríamos hablar de una construcción completiva con preposición.

10 Estos tres últimos ejemplos no corresponderían a verbos de entendimiento y lengua pero los señalamos como muestra de construcción preposicional ante QUE. 
- Forma analítica compuesta por Verbo $S E R+$ adjetivo verbal

dixo Turín al rrey que bien cierto fuese de que eso poco que él sabía que gelo diría... (Lib. Est., I, p. 33)

demas que bien fuese seguro de que, maguer los cristianos eran pocos, que aquel Dios en que ellos creían era muy poderoso (Conq. p. 242)

el fue muy marauillado de quel tremie assy su carne (P.C.G., II, p. 268)

- Verbo + prep. + QUE

... a todos los otros que por so conseio se querien creer de que ellos aurien recebido grandes dannos e recibrien cada día (P.C.G., p. 45, 24a apud Tarr)

E la cosa de quessel mas dolie era de que enueieciera en jogleria et no los sabie bien fazer a su uoluntad; (P.C.G. I, p. 126, 178)

mando un dia dar pregon (...) que fuesen (...) et quel gradeciessen de que no los mandara matar (P.C.G., I, p. 180, 307)

connosçe a Dios el (ye)rro que feziste contra el et gradeçela de que te dexa con tanto (P.C.G. II, p. 658, 1006, nota) ${ }^{11}$

les non fue otorgada la pasada a esos onrrados moros a que mucho peso de que el paso ouieron preso et sse pressos vieron (P.C.G. II, p. 766,1120 )

e a Maynete no pesaba menos de que ella quedaba tan triste; (Conq. p. 184$)^{12}$

quando los hebreos acordaron en que tornassen sobresi non podien ya ca desbaratados los auien los egipcianos (Gen. Est. 28a, p. 296, apud S. García, p. 228)

11 En los dos últimos ejemplos se percibe cierto matiz causal; no obstante, pensamos que el valor completivo es más evidente. Según Tarr (1922), estariamos ante oraciones causales ya que en la época en que escribe su articulo no se considera la posibilidad de un elemento intermedio entre el C.C. y el C.D. Hoy día para tratar de este tipo de complemento nos referimos al Complemento de Régimen Preposicional o Suplemento.

12 Con el verbo pesar la oración introducida por de que tiene la función de sujeto. En espanol medieval es relativamente frecuente, dada la gran perdida de significación que sufren las preposiciones, encontrar sujetos con DE. 
acordaron todos en que las dejasen ir con todo lo suyo en paz (Conq. p. 274)

començo yaquanto de reuellar en cosas contral rey don Alfonsso, su suegro, atreuiendosse en que era casado con su fija et auiendo tamanno debdo con el (P.C.G. II, p. 650, 969) ${ }^{13}$

cuidando en que serié assí, mandó llamar a Moisén de noche e díxoles: (Gen. Est. Ex. XII, XXVI, p. 104)

Algunos hobo entre ellos que hablaron en que debian hacer cualquier partido á los cristianos é que se fuesen de allí. (Conq. p. 166)

penso en que fuesen fasta Hierusalen por ver si hallarian fuera de la villa bestias 6 alguna otra ganancia (Conq. p. 291)

Punno en que la besase pues que mas non podien auer del (Gen. Est. 1. , p. 212, apud S. García, p. 228)

Et el diablo que sienpre se trabaja en que faga el omne lo mas desaguisado, (C. Luc. p. 259)

non paredes mientes a quanto floxamiente voslo ell ruega et non esperades a que vos afinque mas por ello si non por aventura non vos fablara mas en ello (C. LuC. p. 119)

et fue a Constantinopla por fablar con el Emperador sobre que les vendian las cosas que habian menester, mas caras que solian. (Conq. p. 20$)^{14}$

- Los datos con los que contamos no son muchos si los comparamos con la ingente cantidad de construcciones apreposicionales localizadas en los textos medievales. Por razones de espacio no incluiremos más ejemplos de construcción directa en el presente estudio; una importante selección de ella se encuentra en la tesis doctoral que hemos realizado ${ }^{15}$.

13 Según CUERvo, el significado de atreverse es «confiarse».

14 Además de todos los ejemplos mencionados, pueden verse otros casos de prep. + QUE en: Conq. p. 20 (haber pesar de que), P.C.G. I, p. 221, 392 (estar en quexo de que), Corb. p. 191 (dar logar a que), P.C.G. II, p. 609, 934 (pesar de que), P.C.G. II, p. 489, 808 (traer a que), C. Luc. p. 213 (venir a que) y Celes. XIV (esperar a que).

15 Vid. Serradilla Castaño, Ana Marla (1994). 
3. Ya en 1922, F. C. Tarr, en un trabajo de más de 250 páginas, nos habla de la tendencia uniformadora del español, que está ya presente en la época medieval aunque aún es mucho más fuerte la herencia latina.

«In the development of the prepositional complementary clause, three great forces are at work: (I) the analogy to the construction of the nonclausal complement, which finally is completely victorious and gives us the standardized construction characteristic of modern Spanish...» (p. 254)

La tendencia uniformadora del idioma tendrá que luchar, pues, contra esta herencia latina, con la consideración de QUE como subordinante universal, con la similitud con otras lenguas romances etc., y no triunfará, efectivamente, hasta bien entrado el siglo XVII pero en la época medieval, sin embargo, como hemos señalado, se dan ya ejemplos de la construcción preposicional. Pese a los muchos obstáculos con que se encuentra esta construcción para desarrollarse, existen una serie de factores que favorecen su extensión:

3.1. La analogía con las construcciones causales, temporales, etc.

3.2. La influencia de $\approx D E Q U E »$ adverbial.

3.3. La existencia de "EN/DE COMMO» con valor completivo.

3.4. La ambiguiedad con el $Q U E$ relativo.

3.5. La relación con las oraciones interrogativas.

Además existen dos tipos de construcciones que se convierten en un paso previo a la aparición de cláusulas preposicionales tal y como las conocemos hoy en día:

3.6a. Las construcciones del tipo «prep. + pronombre + QUE» en las que el pronombre no tiene ningún valor.

3.6b. Las construcciones prolépticas.

Estos factores influirán en mayor o menor medida en el avance de las construcciones preposicionales ante QUE completivo. A continuación hablaremos brevemente de cada uno de ellos.

3.1. Por una parte, hay que tener en cuenta aquellas expresiones causales, finales, temporales, etc., en las que aparecen preposiciones ante QUE; en estos casos la preposición es necesaria porque no es mera marca de subordinación sino que aporta una significación que QUE, por sí solo, no llega a proporcionar. Este factor nos parece especialmente importante ya que las preposiciones que participan en estas estructuras serán las mismas que aparezcan con 
las completivas de suplemento o de régimen preposicional. Proponemos a continuación algunos ejemplos en los que participan a, de, en o por.

Valor final

Y embïaran sus escuderos y moços a que me acompañassen; (Celes. IX) Et si quier guardarse a que non caya en yerro, segund dize un exenplo que dize que «la cuenta vieja, varaja nueba». (Lib. Est. I, p. 159) soltaron le los emperadores todos los pechos por diez annos de que se refiziesse (la ciudad) (P.C.G. I, p. 152)

\section{Valor causal}

é erró mucho de que non metió sus fijas consigo, (Conq. p. 50) (Et) obieron vergüença porque estavan desnudos, (Lib. Est. I, p. 62) a ti he de gradeģer por que so aun uiua (P.C.G. I, 135b, 15, apud Tarr p. 160)

et esto fazia el por lo matar, ca era de tan grant fuerça... asi que non a omne que con poder de su ualentia abraçase a que non matase. Et el otro non se quiso meter a aquella uentura, en que estaua a morir en seruiçio de Dios (P.C.G. II, 728a, apud Tarr, p. 178) ${ }^{16}$

\section{Valor temporal}

...Mas desaventuradas de que me acabes de oír, porque la paga será tan fiera... (Celes. I)

et Jonas en que lo vido, fue mucho irado, et dixo (S. $P . \mathrm{I}, 4,84$, apud Tarr, p. 177).

\section{Valor locativo}

$\mathrm{E}$ ¿en que lo veedes vos eso? dixo el cavallero amigo - ¿En que? dixo la ynfante. En que vos veo venir muy alegre (Cav. Cif., 293, 8, apud Tarr, p. 164)

La frecuente aparición de estas construcciones deja paso libre a la analogía y a la utilización de preposición ante QUE aunque no aporte ningún valor específico ${ }^{17}$.

16 En que es muy raro con valor causal; en este ejemplo Tarr le da esta interpretación. Recogemos sus palabras: «Here the only interpretation possible for en que is «puesto que», which is a logical development of en que temporal». (p. 178).

17 Como puede observarse, estamos ante una diferencia constructiva dependiendo de que el complemento que siga al verbo vaya regido por él o sea un Compl. Circunstancial. El análisis de 
3.2. También la abundante frecuencia del grupo «DE QUE» adverbial temporal es otro factor que puede influir en la aparición de preposición ante cláusula completiva; en primer lugar influirá, lógicamente, en la aparición de de, y a partir de aquí de otras preposiciones, ya que, formalmente, no se da diferencia alguna entre ambas construcciones. El hablante considera que si en unas ocasiones puede utilizar de que ¿por qué no en los demás casos, cuando, incluso, este uso se ve favorecido por la presencia de preposición ante contextos nominales o de infinitivo?

Observemos algunos ejemplos de de que adverbial:

Agora, de que la estoria a contado desta hueste... (P.C.G. II, p. 696, 1015) Et ellos, de que y llegaron, fezieron... (id, p. 743, 1063)

Hemos mencionado, hasta ahora, el valor temporal de de que, pero este valor no es el único ya que, en ocasiones, Tarr (1922, p. 173-76) ilustra algunos ejemplos en los que de que podía adoptar significados condicionales $o$, incluso, causales o finales:

esto seria verdat de que fuesedes cierto de la cosa, mas fasta que ende seades cierto, consejovos que... (C. Luc. 165,3)

Et de que estas cosas guardedes en lo que ovieredes de fazer et lo fallaredes que es bien et vuestra pro, consejovos que nunca lo dexedes de fazer (id, 18,6)

e los ruanos (...) parense en aquella pontesilla que esta en el camino; e sy menester fuere de que atan cerca sean para que nos puedan acorrer, que nos acorran (Cav. Cif., 49,4)

De que a esta casa viva es allegada/Sennor mercet te clamo que tome meiorada (S. Dom. 302,a)

De que oraron ellos de muy grant femencia/Que que foron los otros de muy firme creencia/Tollo Dios a la duenna la mala pestilencia (id, 616a) En tres cosas hizo Dios gran merced a los cristianos aquel dia: la una de que les dio a ganar tan noble cosa e tan buena como es antioca; la otra, que les harto sus voluntades de matar e robar a sus enemigos; la tercera porque lo enriquecio de muy gran tesoro que ganaron (Conq. 236a) ${ }^{18}$

las características de uno y otro tipo de complemento escapa al objetivo de este estudio; por cuestiones de espacio no nos podemos detener en este tema aunque no por eso dejamos de considerarlo básico. En nuestra tesis doctoral hemos intentado aclarar la situación y proponer una serie de criterios que facilitan la diferenciación.

18 Este último ejemplo, encontrado en la versión de 1503, puede responder a una confusión. Recogemos las palabras de Tarr: «This example being found in that part of the text based solely on 
soltaron le los emperadores todos los pechos por diez annos de que se refiziesse (la ciudad) (P.C.G. 152a, 31)

mandole dar dies camellos cargados de plata, de que comprase aquellos polvos (Cav. Cif., 309,18)

Pensamos que esta amplitud de valores facilita aún más la analogía y, por tanto, la aparición de completivas preposicionales. El hablante es consciente de que esta fórmula se utiliza para expresar diferentes relaciones; no se trata de una formula exclusivamente temporal y, por eso, su paso a otro tipo de construcciones no parece algo extraño o discordante. No decimos con esto que de que sea un factor fundamental para la introducción de preposición ante cláusula completiva pero sí que, unido a otros muchos factores, puede favorecer este fenomeno.

3.3. Otro factor importante es el uso de COMO, con valor similar al QUE completivo, precedido de las preposiciones EN y DE sin ninguna aportación significativa. Estamos ante fórmulas fosilizadas donde la preposición no viene regida por el verbo pero, al ser estas construcciones claramente completivas, es normal que el hablante tienda a utilizar también estas preposiciones cuando el introductor de la completiva no sea COMO sino QUE. El valor completivo de estas construcciones se remonta al latín; recogemos, a continuación, unas palabras muy ilustrativas de Jules Jeanjaquet (1894):

*C'est un fait bien connu qu'après des verbs tels que dire, savoir, montrer et autres sembables comme peut être l'equivalent de que.

Dejà en latin postclassique quomodo s'emploie comme synonyme de quod et quia: dicere quomodo... (...) responderunt quomodo... (...) cognitum habetis quomodo... (...)» (p. 35).

La aparición de las preposiciones EN o DE no parece aportar ninguna diferencia significativa a la construcción en los siguientes ejemplos ${ }^{19}$, existe una gran vacilación y pensamos que puede ser un importante punto de partida para la aparición de preposición en otras construcciones completivas:

the printed version of 1503, may be the result of a sixteenth century confusion between the determinative complementary construction and the causal porque, rather a bona-fide de que causal clause». (p. 175).

19 En algunos casos la preposición irá regida por el verbo - no metio mientes en al si non en commo cayese apuestamientre en tierra... (S.P. 96b, 31, apud Tarr, p. 127); ¿De qué té ries? -De como no conoscias a la madre... (Celes. 52, 28, apud Tarr, p. 127)- pero, como se ha podido observar, son muchos los casos en los que no tiene ninguna justificación. 
oyo una bos que le dixo asy: Levantate e enbia por toda la gente e diles en commo con esta muger fueste ante casado que con la reyna e que oviste en ella aquellos dos fijos, e de commo tu e la reyna mantovistes castidat fasta que Dios ordeno della lo que tovo por bien (Cav. Cif 170, 17, p. 123)

Alo que me pedistes por merced deziendo que vos era fecho entender en commo yo mando tomar... (Doc. Villa. II, 1433, p. 100)

entendio estonce de como adaua el Çid en este pleyto, (P.C.G. II, p. 560, 891)

Entendio Alexandre//cuemo uenie duldando (Alex. 1429a)

3.4. En otros casos, básicamente cuando el elemento rector es un nombre en lugar de un verbo, la aparición de la preposición puede servir para evitar la ambigüedad con el relativo ya que, como indican Bogard y Company (1989), QUE con nombre se interpreta, normalmente, como relativo y con verbo como completivo:

«En el español, además, el nexo que tiene una interpretación preferente como completivo cuando va regido por verbos, y como relativo cuando depende de sustantivos. El cambio analógico a que nos referimos está motivado por el hecho de que la estructura que nos compete muestra una conjunción que con sustantivo pero con valor de completiva. Ante esta situación el sistema ejerce presión para desambiguar la semejanza de esta estructura con las oraciones de relativo, y se extiende así la preposición del esquema con infinitivo al esquema con que y verbo conjugado». (p. 260).

De ahí, pues, se extendería el uso de la preposición a los casos en que el elemento rector es un verbo según, siempre, la hipótesis de los autores mencionados. No creemos que sea un factor determinante ya que pese a la presencia de la preposición la ambigüedad puede mantenerse; recuérdese el siguiente ejemplo:

Sepades que a nos es fecha rrelacion en que vosotros andays de lugar en lugar muchos tiempos e annos (Doc. Villa III, 1499)

No obstante, en unión de los otros factores apuntados, puede influir en la extensión de las construcciones preposicionales ante QUE.

3.5. La entrada de las preposiciones en las construcciones interrogativas es anterior, aunque también tardía, y puede influir en la aparición de preposición ante QUE completivo, ya que existen algunos verbos que rigen completivas e interrogativas. Esta influencia, sin embargo, no es tan clara como las 
anteriormente mencionadas ya que actúa en dos direcciones: en un primer momento, ambas retardan la aparición de preposición pero una vez que empiezan a aparecer interrogativas con preposición, estará abierto el camino a la entrada de preposición ante QUE completivo.

Son muchos los ejemplos en los que se observa la ausencia de preposición en las oraciones interrogativas

e porque fuesen ciertos quales son los nuestros dineros, (Cortes de Alcalá 1348, p. 16)

Desque están dubdando los omnes qué an de fazer, (L.B.A. 642a)

el quinto capítulo fabla qué diferencia ha en(tre) maneras e costumbres. (Lib. Est. I, p. 20)

marauillose mucho que podrie seer, (P.C.G. II, p. 341, 598)

parad vós mientes que deve el omne fazer a Dios, (Lib. Est. I, p. 99)

et se acordó quánto sin miedo et sin duelo desconjuntara la cabeça del muerto, (C. Luc. p. 246)

Y pues somos inciertos cuándo avemos de ser llamados... (Celes. XVI)

pero hay ya algunas documentaciones tempranas que pueden influir en las cláusulas complementarias preposicionales:

he dubdado sobre cuál haré antes: (Cárcel, p. 102)

Fue mucho espantado de quan fuerte era (Cr. Alf. XI, XVII, 31, apud Girón p. 182)

E so mucho maraviellado de quanto as dicho (Sendebar, M. Pidal, 1964:748, apud Girón p. 164)

se maravillaron mucho de cuán pequeño hombre era Pedro el Ermitaño, (Conq. p. 20)

- Hemos mencionado también la existencia de otras dos construcciones que parecen suponer un paso previo a la estructura preposicional de las cláusulas complementarias.

3.6a. Existen unas expresiones, citadas por Tarr (1922), compuestas por prep. + pronombre + que, que son un punto intermedio entre la construcción directa y la preposicional ya que el pronombre que aquí aparece no tiene ningún valor sino que es, simplemente, un elemento que se introduce para evitar esa unión directa entre la preposición y el QUE completivo.

pesandoles mucho de lo que la reyna donna Vrraca su sennora diera las fortalezas et los castiellos al rey de Aragon... (P.C.G. II, p. 647) el rey don Alffonsso de Portogal pesandol et doliendosse daquello 
que el rey don Fernando poblaua Çipdat Rodrigo, enuio don Sancho su fijo primero... con su hueste contra el (id, p. 675)

E Garfin e todos los otros acordaron en esto que el cavallero amigo desie bien (Cav. Cif. 136, 22, apud Tarr, p. 110) ${ }^{20}$

Entonces los condes uuscando... escusas con que se escusassen al rey daquello que non aduzien el ninno encrubiensse... quanto podien (P.G.C. 670a, 51, apud Tarr p. 161) 21

En estos ejemplos el pronombre es totalmente superfluo y no aporta ninguna información a la relación; así, aunque a primera vista podríamos pensar que estamos ante un que relativo relacionado con el pronombre que le antecede, un análisis más detenido nos permite hablar de oraciones completivas.

3.6b. Otras expresiones, las llamadas prolépticas, mencionadas por Tarr (1922) y Menéndez Pidal (1969) en las que se anticipa a la principal un elemento de la subordinada, son también un paso previo a la construcción preposicional ante cláusula.

et fueron seguros dell que non ayudarie a los castellanos... (P.C.G. II, p. 424, 725)

e confiando de vos, (...) que bien e fiel y diligentemente faredes to que por nos vos fuere mandado, (Contrib. p. 70, 1481)

...han cuidado de sus almas que se saluen (Gatos, XXIV, 63 apud Tarr, p. 120)

me maravillo mucho de vos que digäis (Dial. Leng. 410, 13, apud Tarr, p. 120)

auiendo sospechas de sus hermanos quel tomarien el regno (P.C.G. 282b, 24, apud Tarr, p. 120)

ca sse temién de la sennyora que se quería yr ssu vía, (Apol. 593d)

me plaze de Myo Çid que fizo tal ganançia (Cid vv. 885, 1622)

Pensamos que, precisamente, esa anticipación del sujeto a la oración principal se debe a un intento de uniformidad constructiva aunque no se llega aún a la unión directa de preposición y QUE ya que sigue existiendo un elemento intercalado, como ocurría en el punto anteriormente señalado. Estas

20 Respecto a los ejemplos con acordar. Tarr no cree que estemos ante un inicio de cláusula complementaria preposicional: \&It is quite possible that these examples, instead of showing an incipient prepositional complementary clause, are to be interpreted: «en esto (zesta cosa) acordaron que» (p. 140); no obstante, tampoco es evidente su explicacion. Estamos, de todos modos, ante una posible base para la extensión analógica de esta construcción.

21 El significado de los ejemplos mencionados serfa: «le pesaba de que le había dado*, use dolía de que el rey poblaba», kacordaron en que decía», «se escusaba de quew. Como se puede observar, el pronombre no aporta ningún valor en estas construcciones. 
construcciones van desapareciendo a medida que se desarrollan los esquemas preposicionales ante completivas; en El Quijote, de hecho, son ya extrañas. Este desarrollo inversamente proporcional de ambas nos permite afirmar que las construcciones preposicionales van ganando terreno hasta hacer desaparecer a las construcciones prolépticas que ya se observan como innecesarias.

- Todos estos factores que propician, en mayor o menor medida, la construcción preposicional ante QUE completivo, unidos a otros más o menos decisivos como la analogía con las formas analíticas ${ }^{22}$, se daban ya en la Edad Media y es por eso por lo que ya en esta época tenemos los primeros ejemplos de esta construcción.

4. Cuando autores como Bogard y Company (1989, p. 259) hablan de que esta construcción no aparece hasta el siglo XVII no sólo no parecen tener en cuenta la documentación existente sino tampoco los factores que la propician. Además debemos destacar que ya en el siglo XVI, aunque sigue siendo menos frecuente que la construcción directa, es ya muy abundante; basta con acudir al libro de Keniston (1937), al de Tarr (1922), a los trabajos de Cano Aguilar (1977-78, 1985) ${ }^{23}$ o a cualquier documento de la época para observar la presencia de estas construcciones.

- Finalmente, lo que hemos querido destacar en este trabajo es que si los factores que influyen en la persistencia de la construcción directa tienen aún en la época medieval una gran importancia, no por eso hemos de desdeñar otros factores que, poco a poco, se van abriendo camino, en su lucha por llegar a conseguir la uniformidad constructiva característica del español. Esta tendencia uniformadora del español para utilizar el mismo régimen ante los diferentes contextos categoriales — nombre, infinitivo y cláusula- no es, pues, en contra de lo que se ha venido afirmando, un fenómeno tardío, del siglo XVII, sino que comienza a surgir ya en la época medieval favorecido por diversos factores y, como reflejo de esta tendencia, documentamos ya las primeras apariciones de construcción preposicional ante QUE completivo en el siglo XIII, época mucho más temprana que la que, hasta ahora, los diferentes estudiosos habían considerado como fecha de inicio de estas construcciones.

22 No nos detenemos en este artículo en la relación forma analítica-forma simple porque escapa a nuestros objetivos, pero podramos avanzar que la estructura preposicional de las formas analf́ticas ante otros contextos puede facilitar, en un primer momento, la aparición de preposición ante QUE y de ahi, extenderse a las formas simples equivalentes. Estas relaciones no son, sin embargo, tan claras ya que la analogía funciona en ambas direcciones. En nuestra Tesis Doctoral (Serradilla, 1994) hemos analizado con detalle estas relaciones.

23 El trabajo de Cano Agullar (1977-78), junto al de Tarr, puede ser considerado como uno de los más profundos estudios realizados sobre estas construcciones medievales. 
CORPUS DE TEXTOS

Domingo Palacio, T.: Documentos del Archivo General de la Villa de Madrid, Madrid: Imprenta y Lit. Municipal, 4 vols. 1888 (vol. I), 1906 (vol. II), 1907, (vol. III), 1909 (vol. IV).

Millares Carlo, A. y ARTiles Rodríguez, J.: Libros del Acuerdo del Concejo Madrileño (1464-1600), Madrid: Ayuntamiento (Artes Gráficas municipales), 1932, 2 vols.

Millares Carlo, A.: Contribuciones documentales a la Historia de Madrid, Madrid: C.S.I.C., Instituto de Estudios Madrileños, 1971.

Cantar de Mío Cid, Madrid: Espasa-Calpe, 1946, vol. III, ed. paleográfica y crítica de D. Ramón Menéndez Pidal.

Cárcel de Amor de Rodríguez de San Pedro en Obras Completas II, Madrid: Castalia, 1982. (ed. Keith Whinnom).

El Conde Lucanor de don Juan Manuel, Madrid: Castalia, 1982 (4.' ed.) (ed. de J.M. Blecua).

Documentos Lingüísticos de España. I. Reino de Castilla, Madrid: Centro de Estudios Históricos, 1919 (ed. de Menéndez Pidal).

El libro de Alexandre (Texts of the Paris and the Madrid manuscripts prepared with an introduction) ed. de Raymond Willis jr... Princeton University (USA) -París: Presses Universitaires de France, 1934.

General Estoria (Antología) de Alfonso X, Barcelona: Plaza \& Janés, 1984 (ed. Milagros Villar Rubio).

La Gran Conquista de Ultramar, Madrid: Biblioteca de Autores Españoles, (n. ${ }^{\circ} 41$ ), 1951, (notas de D. Pascual Gayangos).

Libro de Apolonio, Madrid: Castalia, 1987, (ed. de Carmen Monedero).

Libro de los Estados de D. Juan Manuel, Oxford: University Press, 1974 (ed., introd and notes R. B. Tate and I. R. Macpherson).

Primera Crónica General de España, 2 vols. Madrid: Gredos, Univ. de Madrid, Fac. Filosofía y Letras, Sem. Menéndez Pidal, 1955, 2." ed. (1906, 1." ed.)

Tragicomedia de Calisto y Melibea de Fernando de Rojas. Introd. y ed. crítica de Miguel Marciales, 2 vols. University of Illinois Press, 1985.

BIBLIOGRAFIA

Bartol Hernández, J. ANTONIO (1988): Las oraciones causales en la Edad Media, Madrid: Paraninfo. 
BOGARD, SERGIO y COMPANY, CONCEPCIÓN (1989): «Estructura y evolución de las oraciones completivas de sustantivo en el español», Romance Philology, vol. XLIII, n. ${ }^{\circ}$ 2, nov., pp. 258-273.

CANO AGUILAR, RAFAEL, (1977-78): «Cambios en la construcción de los verbos en castellano medieval», Archivum, XVII-XVIII, pp. 335-379.

CANO AGUILAR, RAFAEL, (1985): «Sobre el régimen de las oraciones completivas en español clásico", Homenaje a Manuel Alvar, vol. II, pp. 81-93.

DE GoROG, RaLPH y LISA S. (1978): Concordancias del Arcipreste de Talavera, Madrid: Gredos.

GaRcia García, SERAFInA (1990): Los transpositores oracionales en la obra histórica alfonsi (Estudio de Sintaxis Funcional), Oviedo: Universidad, Dpto. de Filología Española.

GIRON ALCONCHEL, JOSÉ LUIS (1988): Las oraciones interrogativas indirectas en español medieval, Madrid: Gredos.

GIRON ALCONCHEL, JosÉ LUIS (1992): «Subordinación sustantiva y discurso indirecto en la prosa medieval», Estudios Filológicos en Homenaje a Eugenio de Bustos Tovar, pp. 363-377.

JEANJAQUET, JULES (1894): Recherches sur l'origine de la conjonction *QUE» et des formes romanes equivalentes, Neuchatel: Libraire Attinger Frères.

Keniston, hayward (1937): The Syntax of Castilian Prose. The sixteenth Century, Chicago: University of Chicago Press.

Ment́ndez Pidal, Ramón (1969): Cantar de Mío Cid, (Vocabulario, Texto y Gramática), 2 vol., Madrid: Espasa-Calpe, (4." ed.).

RAMOS MÉNDEZ, MANUEL (1989): «Formas descompuestas + cláusula completiva objeto en tres textos medievales castellanos", Verba, XVI, pp. 339-356.

SERRAdilla CastaÑo, ANa M.' (1994): Contribución al estudio del régimen de los verbos de «entendimiento y lengua» en español medieval, Madrid: Universidad Autónoma (ed. en microfichas).

TARR, FREDERICK COURTNEY (1922): «Prepositional Complementary Clauses in Spanish with special reference to the works of Pérez Galdós», Revue Hispanique, LVI, pp. 1-264, (reimpr. 1965). 